\title{
On the Annual Variations in the Amplitude of 25-70-Day Intraseasonal Atmospheric Oscillations in Central Africa
}

\author{
Alain Tchakoutio Sandjon 1, 2,3, , Armand Nzeukou ${ }^{2}$ \\ ${ }^{1}$ Department of Computer Science, Higher Technical Teachers Training College (HTTTC), University of Buea, Kumba, Cameroon \\ ${ }^{2}$ Laboratory of Industrial Systems and Environmental Engineering, Fotso Victor Technology Institute, University of Dschang, Bandjoun, \\ Cameroon \\ ${ }^{3}$ Laboratory for Environmental Modeling and Atmospheric Physics, Department of Physics, Faculty of Sciences, University of Yaoundé 1, \\ Yaoundé, Cameroon
}

\section{Email address:}

stchakoutio@yahoo.com (A. T. Sandjon), stchakoutio@gmail.com (A. T. Sandjon)

*Corresponding author

\section{To cite this article:}

Alain Tchakoutio Sandjon, Armand Nzeukou. On the Annual Variations in the Amplitude of 25-70-Day Intraseasonal Atmospheric Oscillations in Central Africa. Earth Sciences. Vol. 5, No. 3, 2016, pp. 39-47. doi: 10.11648/j.earth.20160503.11

Received: May 25, 2016; Accepted: July 13, 2016; Published: July 23, 2016

\begin{abstract}
In this paper we analyzed the annual variations in the 25-70-day intraseasonal atmospheric oscillations in central Africa, for the period 1981-2010, using the Outgoing Longwave OLR data. We then extracted the amplitude time series of the dominant modes of intraseasonal variability in 25-70 days filtered OLR anomalies, using Empirical Orthogonal Functions (EOF) analysis. The EOF analysis has shown that three dominant modes characterized the intraseasonal atmospheric oscillation in Central Africa. The amount of variance explained by these three retained EOFs are 19.3\%, 13.6\% and $11.8 \%$ respectively, and they exhibit higher spatial loading over Northern Congo, Southern Ethiopia, and Southwestern Tanzania, respectively. The analysis of Principal Components (PCs) time series showed that the amplitude and of the intraseasonal oscillations (ISO) exhibit large annual variations. In fact the highest values of ISO amplitude are generally observed during October-April season, and much weakened signal the rest of the year. The fraction of yearly Madden Julian Oscillation (MJO) power, occurring within October-April season are 79.3\%, 77.92\%, 78.73\% for EOF1, EOF2, and EOF3, respectively.
\end{abstract}

Keywords: Rainfall, ISO Variations, Central Africa, Amplitude

\section{Introduction}

It is well-known that climate variability and change is a crucial problem in many tropical regions. Amongst these regions, the central Africa (CA) is particularly attractive interesting because of the variety of its topography and surface conditions. The CA extends from $15^{\circ} \mathrm{S}$ to $15^{\circ} \mathrm{N}$ and $5-45^{\circ} \mathrm{E}$ mainly over the land and part of Atlantic and Indian oceans on its edges. The topography of the region includes Highlands, mountains, Plateaus (Fig. 1a). Furthermore, CA is particularly vulnerable because the majority of its population is rural and practice rainfed agriculture. Then high frequency climate variability, from daily to intraseasonal timescales is a significant source of vulnerability in the region.

The western part $\left(15^{\circ} \mathrm{S}-15^{\circ} \mathrm{N} ; 5-30^{\circ} \mathrm{E}\right)$ of $\mathrm{CA}$ is consisting of the zones of intense precipitation, especially over the Congo Basin (Fig. 1b). In fact, the western central Africa is almost covered by the Congo forest, which keeps this region quite wet within the year. The Eastern part $\left(15^{\circ} \mathrm{S}-15^{\circ} \mathrm{N} ; 30-50^{\circ} \mathrm{E}\right)$ is characterized by widely diverse climates ranging from desert to forest over relatively small areas. The complex topography of the region is an important contributing factor to climate because it leads to the orographically induced rainfall and affect local climates $[1,2]$. This region has suffered from both excessive and deficient rainfall in recent years $[3,4]$. In particular, the frequency of anomalously strong rainfall causing floods has increased. The difference between the East and West boundaries of CA of approximately $3000 \mathrm{~m}$ in surface elevation, and $3000 \mathrm{~mm}$ in annual mean rainfall. Then the 
two subregions (ECA and WCA), separated from each other surface conditions and precipitation (Table 1). by the Rift Valley, are very different in term of topography,

Table 1. Comparison of some geographical features between eastern and western central Africa.

\begin{tabular}{lll}
\hline & Western Central Africa (WCA) & Eastern Central Africa (ECA) \\
\hline Average topography & Lower than $700 \mathrm{~m}$ & Greater than $1500 \mathrm{~m}$ \\
Vegetation & Almost covered by the Congo forest & From desert to minor forests over relatively small areas \\
Mean annual rainfall & Greater then $1600 \mathrm{~mm}$ & Lower than $700 \mathrm{~mm}$ \\
Borders & Rift Valley-Atlantic ocean & Rift Valley-Indian ocean \\
\hline
\end{tabular}

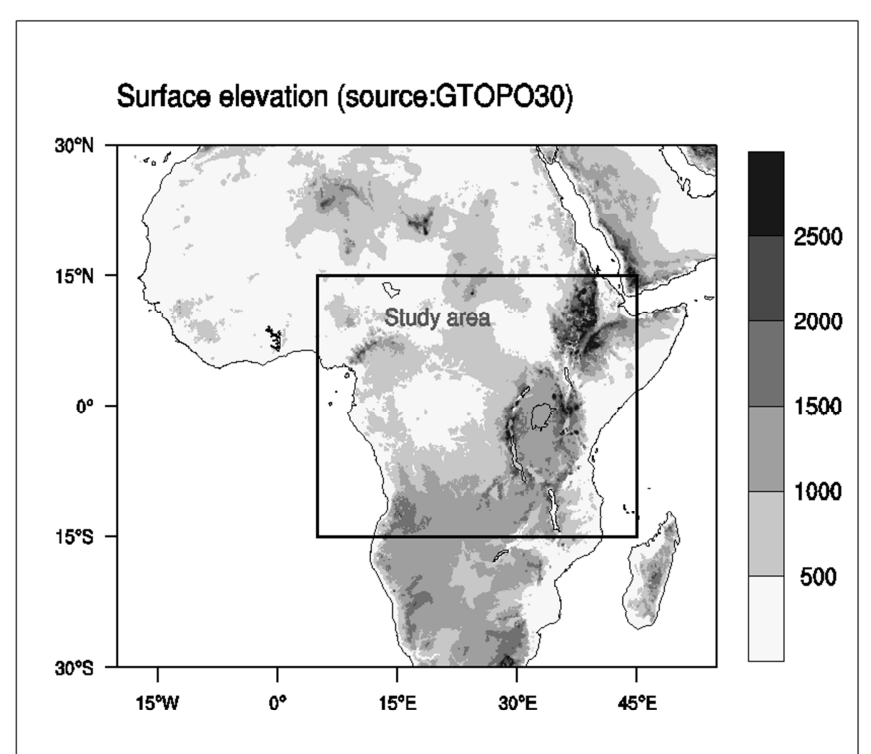

(a)

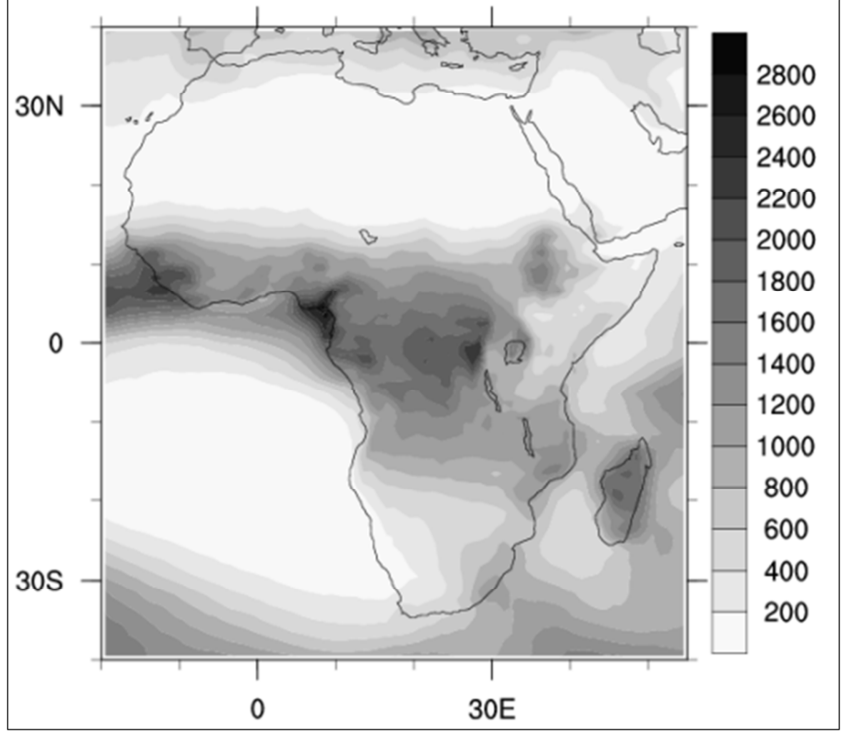

(b)

Fig. 1. (a) Surface elevation over the study area based on 30-min topographic data (m) from Digital Elevation Model (DEM) of the US Geological Survey. The study domain $\left(15^{\circ} \mathrm{S}-15^{\circ} \mathrm{N} 5-45^{\circ} \mathrm{E}\right)$ is shown as solid box. (b) Annual mean rainfall (in mm), based from 1DD GPCP data.

The Inter-Tropical Convergence Zone (ITCZ) is a classical and dominant feature of atmospheric dynamics over the region $[5,6]$. Then the rainfall over $\mathrm{CA}$ is highly seasonal. The peak of ITCZ precipitation belt shifts from north to south of the equator during November-December and returns to north during March-April. The ITCZ precipitation maximizes near $10^{\circ} \mathrm{N}$ during summer, while it peaks near $10^{\circ} \mathrm{S}$ during winter. Around the equator $\left(6^{\circ} \mathrm{S}-6^{\circ} \mathrm{N}\right)$, the mean annual rainfall is divided into four periods or seasons: DecemberFebruary (DJF), March-May (MAM), June-August (JJA), and September-November (SON).

The Madden-Julian Oscillation (MJO) is an intraseasonal fluctuation occurring in the global tropics. It was shown in many studies that MJO is the dominant mechanism of tropical variability at intraseasonal timescales [7, 8, 9, 10, 11, 12, 13], and results in variations in several important atmospheric and oceanic parameters which include both lower- and upper-level wind. The MJO is characterized by eastward propagation of regions of enhanced and suppressed tropical rainfall, primarily over the Indian and Pacific Oceans. The anomalous rainfall is often first evident over the Indian Ocean, and remains apparent as it propagates eastward over the very warm water of the western and central tropical Pacific.

An important characteristic of the MJO (ISO) is its irregularity within the year, and from year to year. In fact the modulation of the level of MJO activity and its possible predictability is one of the greatest challenges and it has been the key subject of many researches (e.g. [14, 15, 16, 17]). However almost all studies on the variations of MJO activity focused on the interannual variations of the signal. For yearto-year variability in MJO activity, many authors found strong interannual modulation of MJO activity, with periods of strong activity followed by periods in which the oscillation is weak or absent $[18,19]$. For example in Central Africa, [17] studied the interannual modulation of ISO activity in Central Africa and the relationships with El Nino Southern Oscillation (ENSO) It is also known that MJO activity exhibits annual variations. For example, here are strong annual variations in the MJO activity, with some months with high intensity signal and other months with low intensity signal. Unfortunately, almost no study has been carried out in Central Africa concerning the variations of ISO activity within the year. The question is addressed in this paper. Some mathematical tools are used to assess the variations patterns of the amplitude of the intraseasonal oscillations in CA within the year.

The paper is organized as follows: In the next section, the data and methods used will be described. Section 3 will present the main results obtained and the analyses. Finally, Section 4 is devoted to a few discussions and conclusions. 


\section{Data and Methods}

\subsection{Data Used}

In this study, the Outgoing Longwave Radiation (OLR) is used as a rainfall proxy. Since 1974, launching polar orbital National Oceanic and Atmospheric Administration (NOAA) and Television Infrared Observation Satellite (TIROS) satellites has made it possible to establish a quasi-complete series of twice-daily measures of outgoing longwave radiation (OLR), at the top of the atmosphere and at a spatial resolution of $2.5^{\circ}$ latitude-longitude [20]. The interpolated OLR dataset [21] provided by the Climate Diagnostics Center has been used here. In tropical areas, deep convection and rainfall can be estimated through low OLR values. Local hours of the measures varied during the period 1979-1990 between 0230 and 0730 in the morning time and between 1430 and 1930 in the afternoon time. Since the deep convection over Central Africa has a strong diurnal cycle [2], the sample of daily OLR based on two values separated by $12 \mathrm{~h}$ is enough to get a daily average. In the tropics where surface temperatures varies modestly trough the annual cycle, the strongest variation in the OLR result from changes in the amount and depth of clouds. This direct physical connection with clouds led to the use of OLR in quantitative precipitation estimation $[2,22,23]$. This product is available on the NOAA website http://www.esrl.noaa.gov and can be freely downloaded.

The Niño-3.4 region $\left(5^{\circ} \mathrm{S}-5^{\circ} \mathrm{N}, 160^{\circ} \mathrm{E}-150^{\circ} \mathrm{W}\right)$ sea surface temperature anomaly (SSTA)index was also used, to define the strength of ENSO and identify individual El Niño and La Niña events [24] These Monthly observed SSTA are adapted from the National Oceanic and Atmospheric Administration (NOAA Climate Diagnostics Center).

\subsection{Methods}

Depending on the purpose of analysis, some frequencies may be of greater interest than others, and it may be helpful to reduce the amplitude of variations at other frequencies by statistically filtering them out before viewing and analyzing the series. The Lanczos filtering [25] used in this study is one of the Fourier methods of filtering digital data. Its principal feature is the reduction of the amplitudes of Gibbs oscillation. The Fourier coefficients for the smoothed response function are determined by multiplying the original weight function $w_{k}$, by a function that Lanczos called "sigma factors". Then the weight function of relation becomes [26]:

$$
\overline{w_{k}}=\frac{\sin 2 \pi k f_{c}}{\pi k} \cdot \frac{\sin \pi k / n}{\pi k / n}
$$

where $w_{k}=\frac{\sin 2 \pi k f_{c}}{\pi k}$ are the traditional Fourier weights.

The Lanczos filter is widely used for filtering climate data time series.

Commonly, some form of time series or spectral analysis is used for extracting periodic signatures from a set of data pertaining to climate variations. Fourier series provides an alternate way of representing data: instead of representing the signal amplitude as a function of time, we represent the signal by how much information is contained at different frequencies. A Fourier series takes a signal and decomposes it into a sum of sines and cosines of different frequencies.

$$
f(t)=a_{0}+\sum_{n=1}^{+\infty} a_{n} \cos (2 \pi n t)+b_{n} \sin (2 \pi n t)
$$

Where $f(t)$ is the signal in the time domain, and $a_{n}$ and $b_{n}$ are unknown coefficients of the series, which can be found by simple integration. In atmospheric sciences, we generally work with discrete data points, not an analytical function that we can analytically integrate. It turns out that taking a Fourier transform of discrete data is done by simply taking a discrete approximation to the integrals. Inversely, the Fourier Transform generates values of amplitudes and phases averaged over the entire time series for each frequency component or harmonic. The amplitude of signal can then be represented as a frequency, and the dominant frequencies are highlighted.

The Wavelet Analysis (WA) is a time series analysis method that has increasingly been applied in geophysics during the last three decades. It is becoming a common tool for analyzing temporal variations of power within a time series. The transformation in time series from the time space into the time-frequency space show that, the WA is able to determine both the dominant timescales of variability and how they vary with time. WA has several attractive advantages over the traditional spectral analysis, especially when dealing with time series with time-varying amplitudes. In contrast to the Fourier Transform, that generates values of amplitudes and phases averaged over the entire time series for each frequency component or harmonic, Wavelet Transform provides a localized instantaneous estimate of the amplitude and phase for each spectral component of the series. This gives WA an advantage in the analysis of non-stationary data in which the amplitude and phase of the harmonic components may change rapidly in time or space. While the Fourier Transform of the non-stationary time series would smear out any detailed information on the changing features, the WA keeps track of the evolution of the signal characteristics throughout the time series. Further details on wavelet analysis can be found in [28].

In the last several decades, meteorologists have in fact put major efforts in extracting important patterns from measurements of atmospheric variables. As a result Empirical Orthogonal Functions (EOF) technique has become the most widely used way to do this [9].

The original purpose of EOFs was to reduce the large number of variables of the original data to a few variables, but without compromising much of the explained variance. Lately, however, EOF analysis has been used to extract individual modes of variability (eg. [7, 9, 13, 17, 28, 29]) in data time series. In the EOF analysis, the time-dependent 
deviations from the long-term mean are decomposed into a sum of products of fixed spatial patterns $p_{k}$ and timedependent amplitudes $\boldsymbol{\alpha}_{\boldsymbol{k}}$ (the principal components) as follows:

$$
f\left(x_{i}, t\right)=\sum p_{k}\left(x_{i}\right) \alpha_{k}(t)
$$

Where the principal components $\alpha_{k}$ are uncorrelated to one another and described subsequently a maximum of variance in the original anomalies field $f$. Under these conditions the EOFs $p_{k}$ are eigenvectors of the covariance matrix of $f$.

The eigen value $\lambda_{\mathrm{k}}$ corresponding to the $\mathrm{k}^{\text {th }}$ EOF gives a measure of the explained variance by $\boldsymbol{\alpha}_{\boldsymbol{k}}$. It is usual to write the explained variance in percentage as:

$$
\text { 100. } \frac{\lambda_{k}}{\sum_{i=1}^{p} \lambda_{i}} \%
$$

Rotated EOF (REOF) is a technique simply based on rotating EOFs. REOF techniques have been adopted by atmospheric scientists since the mid-eighties as an attempt to overcome some of the previous short comings such as the difficulty of physical interpretability. The technique, however, is much older and goes back to the early forties. The technique is also known in factor analysis as factor rotation and aims at getting simple structures. In meteorology, he objective was to alleviate the strong constraints of EOFs, namely orthogonality/ uncorrelation of EOFs/PCs, domain dependence of EOF patterns (see e.g., Dommenget and Latif, 2002), obtain simple structures, and be able to physically interpret the patterns. Initially, a standard EOF analysis is performed and an EOF subset is retained; and subjected to varimax rotation. Some think that the resulting patterns are more physically interpretable. The patterns may still be domain dependent.

The above described mathematical tools (Lanczos filtering, Fourier analysis, wavelet analysis and EOFs analysis) are simultaneously used in this paper. Briefly the long-term OLR anomalies are firstly passed through the highpass Lanczos filter with 120 days cut off in order to remove low frequencies modes such as inter-seasonal and interannual variability. Morlet wavelet is applied to the output time series to extract the relevant information. After the wavelet analysis, the timescales where the intraseasonal signal power is relatively high are detected. The original time series are now passed through a band-pass Lanczos filter to retain only the cycles with periods within the relevant timescales. The filtered data-sets then have been subjected to EOF analysis with varimax rotation and the leadings PCs are retained according to the Scree test [31] and the North criteria [32]. After the PCs time series have been extracted, the variations in the ISO magnitude and was studied using statistical methods.

\section{Results and Analyses}

\subsection{Spectral Analysis}

For every day and each of the two datasets, we averaged the 120 days cut-off high-pass filtered OLR values, of all grid points in the study area to have a mean value. The classical Fourier analysis was then performed on the obtained daily time series. The power spectrum of this time series (Fig. 2) reveals the importance of the intraseasonal variability present in the Central African climate. At intraseasonal time scales, the strongest peaks of convective variability are centered near 50 days and extended over the longer periods (20-80days, corresponding to the frequencies of $0.0125-0.05 \mathrm{day}^{-1}$ ).

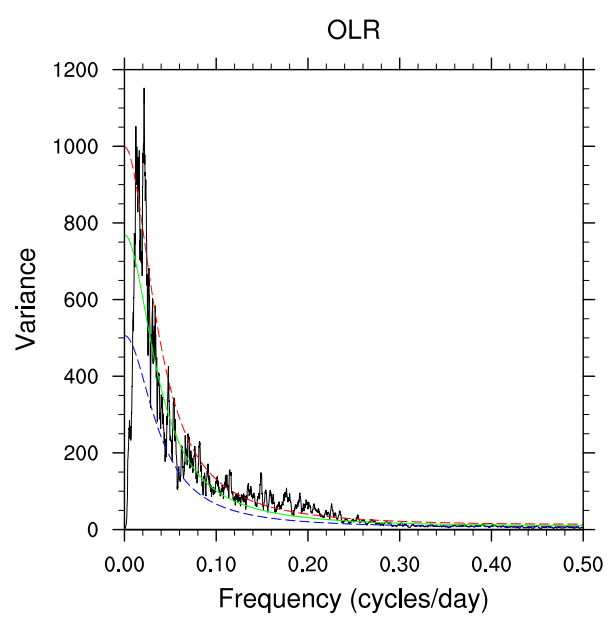

Fig. 2. Calculated spectrum (solid black line), red noise curve (green solid line) and the curves indicating the upper (red dashed line) and lower (blue dashed line) confidence bounds for the period 1981-2010, using OLR data.

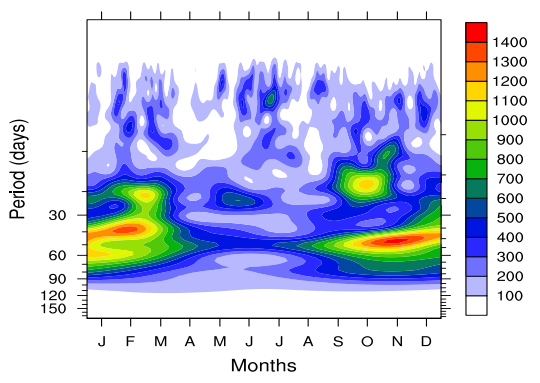

Fig. 3. Annual mean wavelet power spectrum of the rainfall anomalies averaged over CA. A 120-day cut off low-pass filter was applied to longterm anomalies in order to remove low-frequency modes such as interseasonal and interannual variability.

As stated in the previous section, wavelet analysis is an attractive tool for analyzing temporal variations of power within a time series because it keeps track of the evolution of the signal characteristics throughout the time series. Figure 4 shows the wavelet spectrum for the OLR data, obtained from the wavelet analysis applied on the averaged time series described above, and following the technique described by [27]. To show how the signal varies throughout the year, the 
wavelet power was computed on the entire time series (19812010), and the daily climatology was calculated at each frequency, to plot the annual cycle (Fig. 3). It clearly appears that, high wavelet powers are much concentrated at intraseasonal timescales (20-80 days), in consistency with the classical Fourier analysis of Fig. 2. The seasonality of intraseasonal oscillations is clearly defined, since the maximum power during the beginning and end of the year (October-April) and much weakened or no signal during June-September period. This seasonality can be explained by the location of the study area along the equator [35]. A frequency band of the highest wavelet powers is highlighted in the plot. This band is centered near a period of 50 days. This result confirms that the dominant component of intraseasonal atmospheric variability in Central Africa is MJO [30].
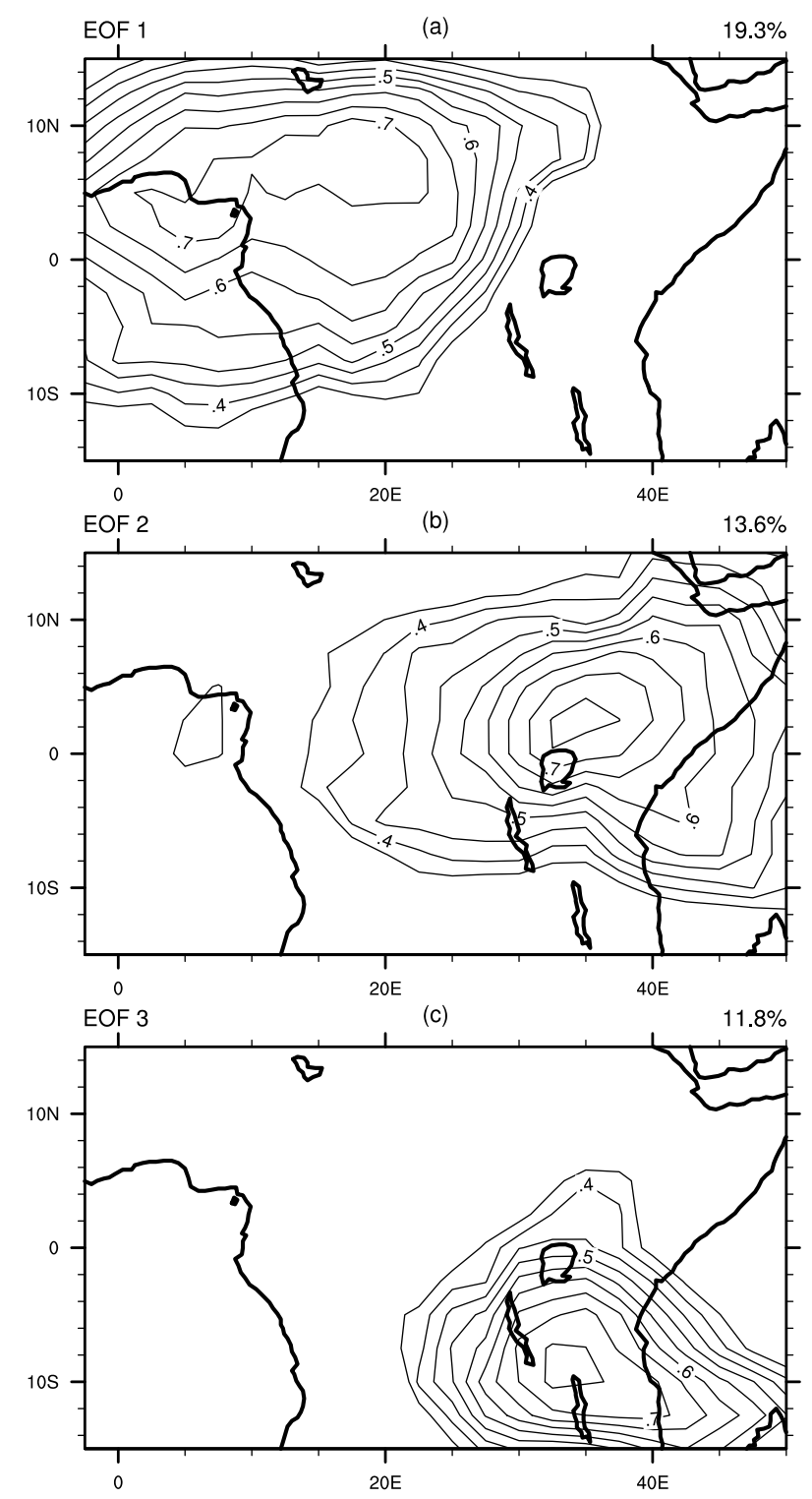

Fig. 4. Correlation coefficient map (loadings) between anomalies field and PCs. PCs were computed using the daily data for the period 1996-2009. Contour intervals are plotted every 0.05 and correlations in between -0.3 and 0.3 are omitted. The negative correlations are represented as dashed line and the positive correlations as solid lines.

\subsection{Annual Variations of 25-70-Day ISO Amplitude}

In previous studies, it was shown that the MJO amplitude exhibits large annual and interannual variations, especially in the eastern part of our study area. To study the annual variations of ISO strength, we therefore the leading modes of intraseasonal variability in central Africa, following the methods described in the previous section. After the data time series have been passed into a band-pass filter with 25-70days frequency bands, we applied the EOF analysis to the filtered data, and according to the Scree test and North criteria we retained only the three EOFs. Figure 4, 5 and 6 show respectively the spatial loadings, the PCs time scores and the power spectra of the three modes retained. These three EOFs (EOF1, EOF2 and EOF3) explain 19.3\%, 13.6\% and $11.8 \%$ of the total intraseasonal variance. The first mode, referred as "Northern Congo mode" exhibits positive loadings centered over northern Congo basin and covers almost the Congo forest. The second, referred as "Ethiopian mode" exhibits positive loadings centered over southern Ethiopia. The third mode, referred as "Tanzanian mode" exhibits positive loadings centered over southwestern Tanzania (Fig. 4). The PCs time series associated with these modes exhibit annual and interannual variations (Fig. 5). These variations are much pronounced in FOF2 and EOF3, compared with EOF1. The correlation coefficients computed 2 by 2 , between these PCs showed that only EOF2 and EOF3 time series are highly correlated, with a correlation coefficient of 0.61. The correlation coefficients EOF1-EOF2 and EOF1-EOF3 are very weak $(-0.16$ and -0.22 , respectively). The power spectra of all the PCs peak around 40 days, suggesting a MJO signal (Fig. 6).

Since the ISO undergo harsh variations within the year, we address the question in this study by plotting the ISO strength in CA during the study period. In order to study much quantitatively these variations, an MJO index was built, by taking the total daily 25-70-day wavelet powers, of the leading principal components. Fig. 7 shows the variations of daily ISO indices for the period 1981-2010. It can be easily seen from this figure that the ISO exhibits high annual and interannual variations. In Table 2 are shown the monthly mean normalized values of 25-70-day ISO power, for the three leading PCs. For each month, we averaged the daily climatology mean power to have a monthly mean value. For the three EOFS, the ISO strength exhibits higher monthly variations. The coefficient of variation (defined as the ration of mean by the standard deviation of a time series), as a measure of dispersion, helps compare variation across variables with different units or different scales. For all months, the values of the coefficient of variation are very high, as they are in majority close to $100 \%$. This observation confirmed the strong annual and interannual variations of ISO activity. The higher ISO amplitudes are observed during the beginning and the end of the year (October-April). In table 3 are presented the fraction of the total yearly ISO power, which occurred within this season. For the three EOFs, more than $70 \%$ of the total yearly ISO powers occur 
during October-April $(79.73 \%, 77.92 \%$, and $78.3 \%$ for EOF1, EOF2 and EOF3, respectively).
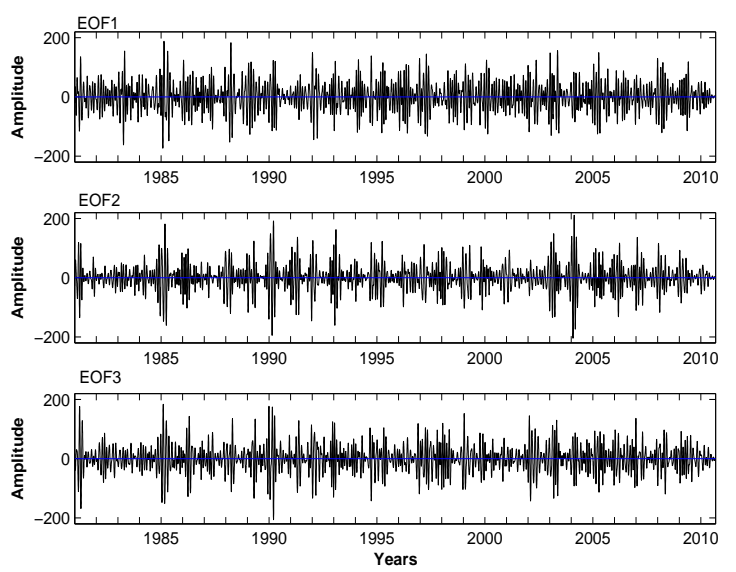

Fig. 5. Time series of the amplitude of the three leading PCs. The EOFs analysis was performed on the entire period (1981-2010). The amplitudes are in $W . m^{-2}$ and the plot formats are identical.

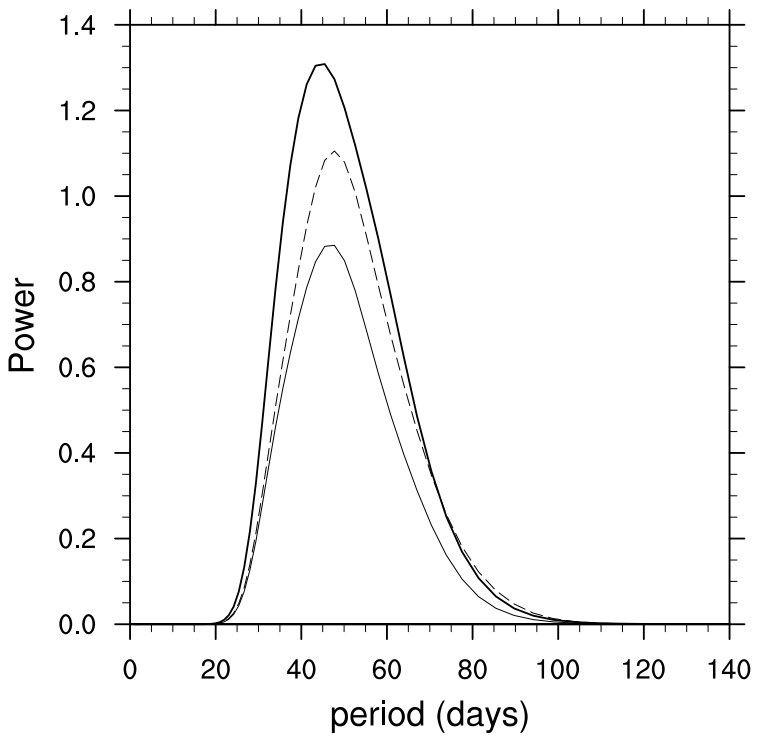

Fig. 6. Power spectra of PC1 (bold solid), PC2 (thin solid), and PC3 (thin dashed), respectively. The scale of the $x$-axis is in days and the power dimensionless because the anomalies field is normalized.

Table 2. Monthly statistical values (mean, standard deviation, coefficient of variation) of ISO power, for the three leading PCs.

\begin{tabular}{lllllll}
\hline & EOF1 & EOF2 & EOF3 & Mean & $\begin{array}{l}\text { Standard } \\
\text { deviation }\end{array}$ & $\begin{array}{l}\text { Coefficient } \\
\text { of Variation }\end{array}$ \\
\hline Jan & 0.62 & 0.50 & 0.44 & 0.52 & 0.39 & 0.90 \\
Feb & 0.67 & 0.54 & 0.47 & 0.58 & 0.43 & 0.92 \\
Mar & 0.65 & 0.59 & 0.57 & 0.60 & 0.45 & 0.87 \\
Apr & 0.47 & 0.48 & 0.43 & 0.46 & 0.38 & 0.73 \\
May & 0.29 & 0.30 & 0.33 & 0.30 & 0.26 & 0.63 \\
Jun & 0.21 & 0.27 & 0.25 & 0.24 & 0.14 & 0.54 \\
Jul & 0.16 & 0.10 & 0.09 & 0.12 & 0.08 & 0.50 \\
Aug & 0.14 & 0.09 & 0.08 & 0.10 & 0.09 & 0.71 \\
Sep & 0.12 & 0.11 & 0.09 & 0.11 & 0.13 & 1.04 \\
Oct & 0.25 & 0.29 & 0.31 & 0.28 & 0.12 & 0.77 \\
Nov & 0.35 & 0.40 & 0.38 & 0.38 & 0.15 & 0.59 \\
Dec & 0.61 & 0.57 & 0.51 & 0.56 & 0.45 & 0.88 \\
\hline
\end{tabular}

Table 3. Distribution of the total annual ISO power, for October-April and May-September seasons.

\begin{tabular}{llll}
\hline & EOF1 & EOF2 & EOF3 \\
\hline October-April & $79.73 \%$ & $77.92 \%$ & $78.73 \%$ \\
May-September & $20.27 \%$ & $22.08 \%$ & $21.27 \%$ \\
\hline
\end{tabular}

This seasonality of ISO is illustrated in the plots of figures 8 and 9. In figure 8, are represented the monthly mean normalized ISO powers, and in figure 9 are plotted the anomalies (deviation from the monthly mean). One may note in figure 9 that the anomalies are almost positive during October-April and negative during May-September. But this seasonality is much pronounced in the Eastern part of the region (EOF2 and EOF3). We also represented the cumulative percentage mean power, as function of the day of the year (Fig. 10). Once again, it can be seen that in the eastern part of the region (EOF2 and EOF3), the ISO activity is highly seasonal. For these two EOFs, this percentage increases rapidly with time between 0-100 days, where cumulative percentage mean power from these 3 months rises from 0 to approximately $70 \%$ for EOF2 and EOF3 and only $62 \%$ for EOF 1 . This value remains roughly constant between 100-280 days (mid-October).
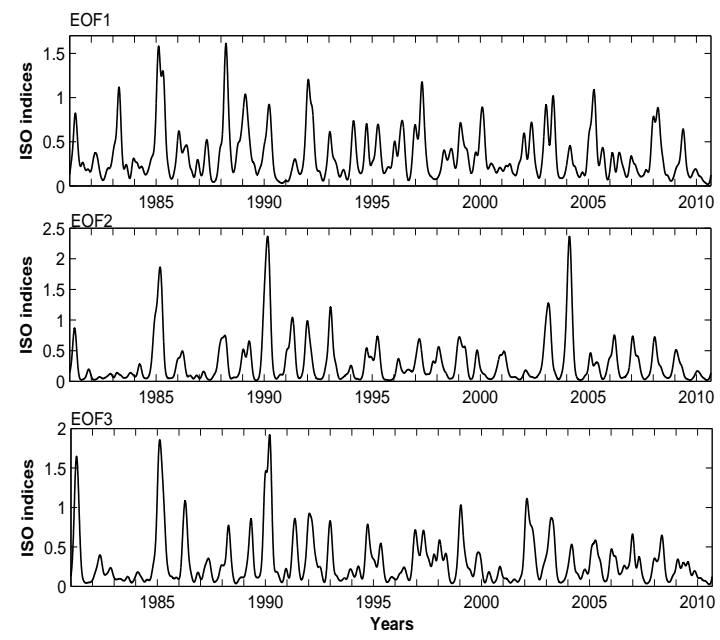

Fig. 7. Time series of MJO index within the period 1981-2010.

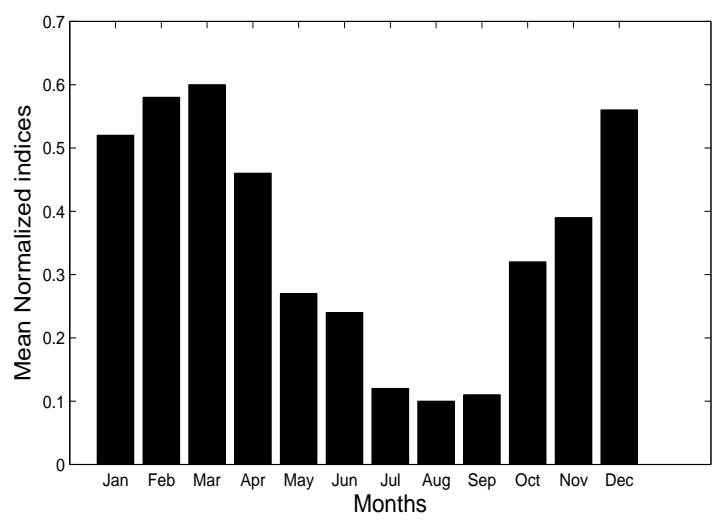

Fig. 8. Monthly variations of averaged power of 25-70-day intraseasonal oscillations, deduced from the three leading PCs. 


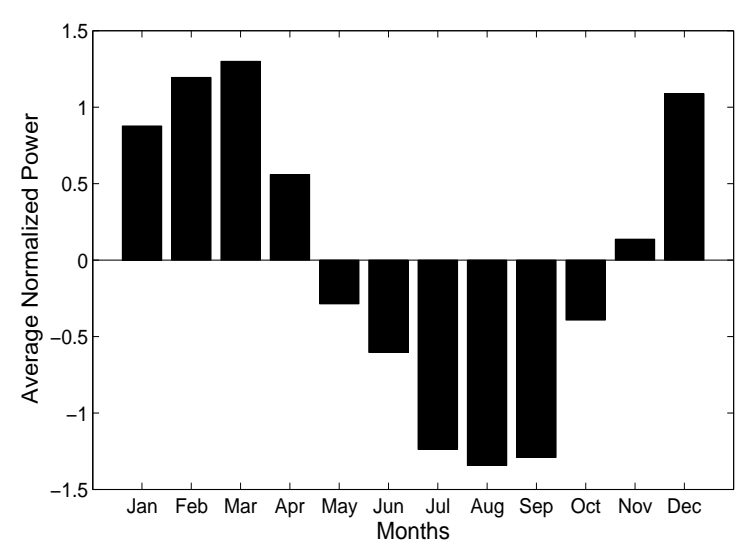

Fig. 9. Monthly anomalies of the 25-70-day mean ISO power, for the three leading PCs.

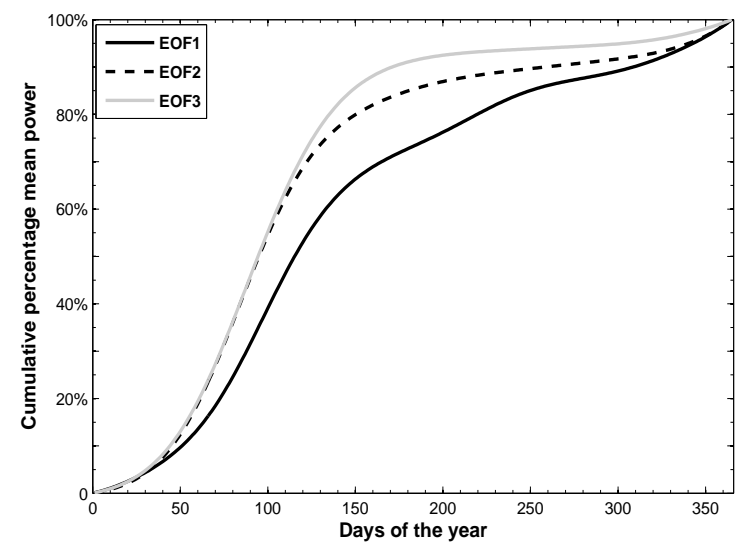

Fig. 10. Cumulated percentage mean ISO power for EOF1 (thin black), EOF2 (black dashed), and EOF3 (gray).

To have more information about the onset and decay of ISO activity, i.e. the period of the year corresponding to high ISO strength, we introduced in this study an index called Index of Variation of ISO Strength (IVS). The determination of this index is based on the rate of the variations of ISO power within two consecutive time intervals. Let's consider $P$ $\left(t_{i-1}\right), P\left(t_{i}\right)$ and $P\left(t_{i+1}\right)$, the ISO power at time steps $t_{i-1}, t_{i}$ and $t_{i+1}$, respectively. The Index of Variation of ISO Strength (IVS) for the $i^{\text {th }}$ day is given by:

$$
I V S=\frac{P\left(t_{i+1}\right)-P\left(t_{i}\right)}{P\left(t_{i}\right)-P\left(t_{i-1}\right)}
$$

Then from the equation 4, an abrupt increase (resp. decrease) of the IVS can be interpreted as the onset (resp. decay) of ISO activity. A value of CVS close to one can be interpreted as a permanent regime (high or low season), while an abrupt change indicates a change in the ISO regime. Figure 11 shows the evolution of IVS throughout the year. As we could expect from Figure 10, the seasonality of ISO is not clearly defined for EOF1, since the graph of variations of IVS revealed many abrupt changes. But all this changes are observed between 100-282 days. For EOF2 and EOF3, the seasonality is clearly defined, as we can observe only 2 abrupt changes on the plots, corresponding to onset and decay of ISO activity. The onset and decay dates for ISO activity, as defined above, are shown in table 4. This table confirmed that ISO activity exhibits higher amplitude during October-April season.

Table 4. Average onset and retreat dates for ISO activity, using IVS.

\begin{tabular}{lll}
\hline & Average onset date & Average decay date \\
\hline EOF1 & Day $285\left(12^{\text {nd }}\right.$ October $)$ & Day $99\left(08^{\text {th }}\right.$ April $)$ \\
EOF2 & Day $279\left(05^{\text {th }}\right.$ October $)$ & Day $92\left(01^{\text {st }}\right.$ April $)$ \\
EOF3 & Day $273\left(01^{\text {st }}\right.$ August $)$ & Day $94\left(04^{\text {th }}\right.$ April $)$ \\
\hline
\end{tabular}
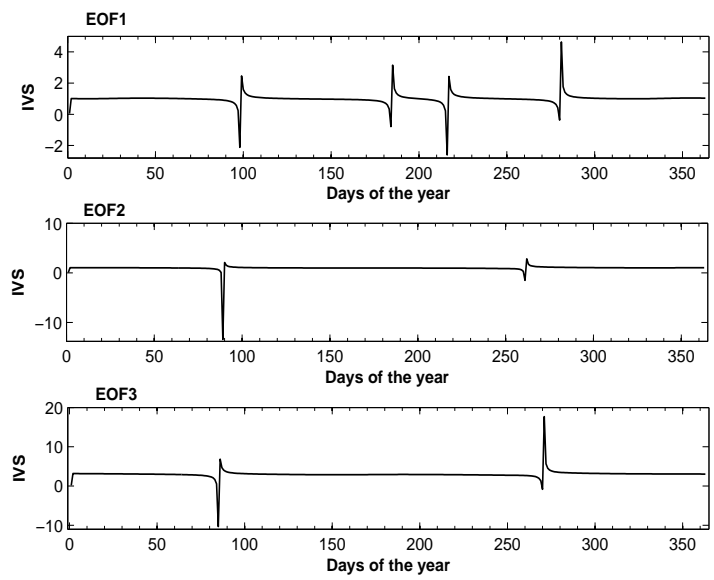

Fig. 11. Evolution of the Index of Variation of ISO Strength (IVS) throughout the year.

\section{Summary and Conclusions}

In this study, we examined the annual variations in the 2570-day intraseasonal oscillations of convective activity over central Africa, using the daily Outgoing Longwave Radiation datasets, for the period 1981-2010. A spectral analysis indicates that the intraseasonal variability is dominated by 20-80 days periods band, with center near 40-50 days, revealing that $\mathrm{MJO}$ could be the dominant component of intraseasonal variability over CA during the last three decades. A wavelet analysis also showed that intraseasonal precipitation variability in CA is dominated 20-80 days timescales with significant spectral peaks centered around period of 40 days, in consistency with the classical Fourier analysis. The seasonality of the ISO power is evident from wavelet analysis, showing the maximum power at the beginning and end of the year (October-April).

We extracted the ISO amplitude time series from EOF analysis, with varimax rotation. In fact, EOF analysis of 25 70-day band-pass filtered OLR anomalies revealed three leading modes of intraseasonal variability over central Africa, called Congo mode, Ethiopian mode, and Tanzanian mode respectively with periods in the MJO timescales. The first mode exhibits high positive loadings over Northern Congo, the second over Southern Ethiopia and the third over Southwestern Tanzania, and they explain $19.3 \%, 13.6 \%$, and 
$11.8 \%$ variance respectively. These amplitude time series revealed seasonality, defining highest amplitudes of ISO during the October-April season.

In order to study more quantitatively the variations ISO strength, an index was built by averaging the 25-70-day power for every day and each EOF mode. The plot of these indices showed that for the three EOFs, the ISO strength undergoes large annual variations. The highest ISO powers are observed during October-April, as already observed from ISO amplitude time series.

One major conclusion emerging from this study is three dominant EOFs characterized the intraseasonal rainfall variability in central Africa, during the last three decades. The analyses of PCs time series revealed that for the three EOFs, the ISO amplitude undergo large annual variations, showing strong signal during October-April, and much weakened signal the rest of the year. But these variations are much pronounced in the eastern central Africa (ECA), when compared with Western Central Africa (WCA). Until more consistent results, the challenge remains the ability of models to accurately simulate both annual and interannual trends in ISO activity, for improving rainfall predictions in the tropics.

\section{Acknowledgements}

Most of the scripts used in this study were produced from the NCL website http://www.ncl.ucar.edu. The GPCP and OLR data was obtained from the NOAA website, http://www.esrl.noaa.gov. All the administrator members of these websites are gratefully acknowledged for maintaining the updated data. We also thank the senior researchers of LEMAP and LISIE for helpful comments.

\section{References}

[1] Thomas, M.; John, C. H. C.; Alexander, G.; Nicolas J. C. Temporal precipitation variability versus altitude on a tropical high mountain: Observations and mesoscale atmospheric modeling. Q. J. R. Meteorol. Soc.2009, 135, 1439-1455.

[2] Vondou, D. A; Nzeukou, A.; Lenouo, A., Mkankam, K. F. Seasonal variations in the diurnal patterns of convection in Cameroon-Nigeria and their neighboring areas. Atmos.sci. Let. 2010, 11, 290-300.

[3] Moore, A.; Ioschnigg, J.; Webster, P.; Leben, R. Coupled ocean-atmosphere dynamics in the Indian ocean during 19971998. 2010, J. climate, 401, 356-360.

[4] Mutai, C.; Hastenrath, S.; Polzin, D. Diagnosing the 2005 drought in equatorial east Africa. J. Climate, 20, 4628-4637.

[5] Mitchell, T. P.; Wallace, J. M. The annual cycle in equatorial convection and sea surface temperature. J. Climate, 1992, $1140-1156$.

[6] Tsuneaki, S. Seasonal variation of the ITCZ and its characteristics over central Africa. Theor. Appl. Climatol, 2011, 103, 39-60.
[7] Madden, R. A.; Julian, P. R.; Observations of the 40-50 day tropical oscillation: A review. Mon. Wea. Rev., 1994, 122, 814-837.

[8] Yamagata, T.; Hayachi, Y. A simple diagnostic model for the 30-50 days oscillation in the tropics. J. Meteorol. Soc. Jpn, $1984,62,709-717$.

[9] Jury, M. R.; Mpeta, J. Intraseasonal convective structure and evolution over tropical East Africa. Climate Res., 2010, 17, 83-92.

[10] Jones, C.; Higgins, R. W.; Waliser, D. E.; Schem, J. K. E.; and Carvalho, L. M. V. Climatology of tropical intraseasonal convective anomalies.1979-2002. J. Climate, 1999, 17, 523539 .

[11] Harry, H. H.; Chindong, Z. Propagating and Standing components of the Intraseasonal Oscillation in Tropical Convection. J. Atmos.sci, 1996, 54, 741-751.

[12] Camberlin, P. and Pohl, B. Influence of the Madden-Julian Oscillation on east African rainfall. Part I: Intraseasonal variability and regional dependency. Int. J. climatol, 2006, 132, 2521-2539.

[13] Maloney, E. D.; Jeffrey, S. Intraseasonal Variability of the West African Monsoon and Atlantic ITCZ. J. climate, 2008, 21, 2898-2918.

[14] Slingo, J. M.; Rowell, D. B.; Sperber, K. R.; Nortley, F. On the predictability of the inner annual behavior of the MaddenJulian Oscillation and its relationship with El Niño, Q. J. R. Meteorol. Soc., 1999, 125, 583-609.

[15] Kessler, W. EOF Representations of the Madden-Julian Oscillation and its connection with ENSO. J. Climate, 1999, 14, 3055-3061.

[16] Hendon, H. H.; Wheeler, M.; Zhang, C. Seasonal dependence of the MJO-ENSO relationship, J. Climate, 2007, 20, 531543.

[17] Tchakoutio, A. S.; Nzeukou, A.; Tchawoua, C. Intraseasonal atmospheric variability and its interannual modulation in central Africa. Meteorol Atmos Phys, 2012, 117, 167-179.

[18] Hendon, H. H.; Zhang, C.; and Glick, J. Interannual variation of the Madden Julian oscillation during austral summer, $J$. Climate, 1999, 12, 2538-2550.

[19] Zhang, C.; Hendon, H., Glick, J. Interannual variation of the madden-julian oscillation during austral summer. J. Climate, $1999,12,2538-2550$.

[20] Gruber, A.; Krueger, A. F. The status of the NOAA outgoing longwave radiation data set. Bull. Amer. Meteor. Soc, 1984, $65,958-962$.

[21] Liebmann, B.; Smith, C. A. Description of a Complete (Interpolated) Outgoing Longwave Radiation dataset. B. Am. Meteorol. Soc, 2001, 77, 1275-1277.

[22] Arkin, P.; Richards, F. On the relationship between satelliteobserved cloud cover and precipitation. Mon. Wea. Rev, 1981, 109, 1081-1093.

[23] Arkin, P. A.; Meisner, N. The relationship between large scale convective rainfall and cold cloud over the Western Hemisphere during 1982-1984. Mon. Wea. Rev, 1982, 115, 51-74. 
[24] Arkin, P. A.; Xie, P. Global monthly precipitation estimates from satellite-observed Outgoing Longwave Radiation. $J$. Climate, 1997, 9, 840-858.

[25] Lanczos, C. Applied Analysis. Prentice-Hall, 1956, 539pp.

[26] Duchon, C. E. Lanczos filtering in one and two dimensions. $J$. Appl. Meteor.1979, 18, 1016-1022.

[27] Torrence, C.; Compo, G. P. A practical guide to wavelet analysis. Bull. Amer. Meteor. Soc., 1998, 79: 61-78.

[28] Tchakoutio, A. S.; Nzeukou, A.; Tchawoua, C.; Kamga, F. M.; Vondou, D. A comparative analysis of intraseasonal variability in OLR and 1DD GPCP data over central Africa," Theoretical and Applied Climatology, 2013a, 116, 1(2), 37-49.

[29] Tchakoutio, A. S.; Nzeukou, A.; Tchawoua, C.; Sonfack, B.; Siddi, T. Comparing the patterns of 20-70 days intraseasonal oscillations over Central Africa during the last three decades. Theoretical and Applied Climatology, 2013b, DOI: 10.1007/s00704-013-1063-1.
[30] Matthew, C. W.; Harry, H. H. An all-season real-time multivariate MJO Index: Development of an index for monitoring and prediction Mon. Wea. Rev., 2004, 132, 19171932.

[31] Tang, Y.; Yu, B. An analysis of nonlinear relationship between the MJO and ENSO, J. Geophys. Res. Ocean. 2010.

[32] Cattell, R. B. The scree test for the number of factors, Multivariate Behavioral Res.1996, 1(2), 245-276.

[33] North, G. R. and co-authors. Sampling errors in the estimation of empirical orthogonal functions, Mon. Wea. Rev., 1982, 110, 699-706.

[34] Trenberth, K. E. The definition of El Niño. Bull Am Meteor Soc., 2010, 78, 2771-2777.

[35] Rui, H. and Wang, B. Development characteristics and dynamic structure of tropical intraseasonal convection anomalies, J. Atmos. Sci., 2010, 47, 357-379. 